\title{
Pellagra and mental disturbance
}

By J. W. T. Dickerson and Josephine Wiryanti, Division of Nutrition and Food Science, Department of Biochemistry, University of Surrey, Guildford, Surrey GU2 ${ }_{5} \mathrm{XH}$

Pellagra is a complex metabolic disorder which is commonly characterized by the three ' $D$ 's: dermatitis, diarrhoea and dementia. We can thus find the effects of the disease in the skin, alimentary tract and central nervous system. There is a certain sequence in which the various clinical manifestations develop (Wood, r 912) with the skin changes appearing first and being exacerbated by exposure to sunlight. These changes are reversed by treatment with nicotinamide, whereas recovery from the manifestations in the central nervous system that occur rather later, is slow and may be incomplete. Patients with severe untreated pellagra develop cachexia, and death occurs within a few months. A disease similar to human pellagra, 'black tongue,' can be produced in dogs, and Elvehjem and his colleagues (Elvehjem, Madden, Strong and Woolley, 1937) showed that both conditions could be cured with nicotinic acid which was thus identified as the pellagra-preventing, or $\mathrm{PP}$, factor.

Pellagra occurs mainly in populations for whom maize is the staple food and in the peoples of the Deccan plateau in Hyderabad where millet (jowar; Sorghum vulgare) is the staple. It may also occur as a complication of other conditions (Hartnup's disease, acute intermittent porphyria, carcinoid tumours), and may be induced by the drug Isoniazid (isonicotinic acid hydrazide). The aetiology of pellagra is complicated and there is some doubt as to whether the human disease is a pure nicotinic acid deficiency. Truswell, Hansen \& Wannenburg (1968) commented on the fact that the disease is often compounded by associated clinical and biochemical features including low serum albumen and urinary riboflavin.

\section{Mental disturbance in pellagra}

Maize is deficient in tryptophan from which the body can make nicotinic acid, and much of the nicotinic acid in maize is in a bound and unavailable form. Tryptophan is also the precursor of brain serotinin and these dietary deficiencies could thus be the cause of the mental changes in pellagra. However, there is some evidence (Gopalan \& Jaya Rao, 1975) that, as in the populations that consume jowar, a high leucine intake may be involved in the aetiology of the disease. In patients with pellagra, and in healthy volunteers, oral leucine has been shown to cause a disturbance in tryptophan metabolism (Belavady, Srikantia \& Gopalan,

- Colombo Plan Scholar, Government of Indonesia. 
I 963 ). Feeding ro $\mathrm{g}$ or more of leucine for I week worsens mental symptoms of pellagrins and is accompanied by changes in the electroencephalogram (EEG). Quinolinic acid ( $\mathrm{g} / \mathrm{d}$ ) has similar effects in pellagrins and these are reversed by nicotinic acid. Neither leucine nor quinolinic acid induce clinical or EEG changes in non-pellagrins (Srikantia, Reddy \& Krishnaswamy, 1968).

Feeding a maize diet to rats rapidly reduces the concentrations of tryptophan, serotonin and 5-hydroxyindoleacetic acid in the brain (Zambotti, Carruba, Vicentini \& Mantegazza, I 975). These changes are reversed by tryptophan, but not by nicotinic acid. These observations are in agreement with others (Dickerson 8 Pao, 1975) which show that brain serotonin is susceptible, amongst other things, to the amount of tryptophan in the diet. Similar measurements do not appear to have been made in the brains of patients dying of pellagra, but the platelet is a useful tool for the study of biogenic amines in man since it shares a number of properties with synaptosomes (Stahl, I977). Platelet serotonin levels were lower in Hyderabad pellagrins with mental depression as compared to normal subjects or pellagrins whose mental state was apparently normal (Krishnaswamy \& Ramana Murthy, 1970). The Indian workers have shown that adding $30 \mathrm{~g}$ leucine/kg to the diet of rats greatly reduces brain serotonin concentrations (Krishnaswamy \& Raghuran, 1972). This effect is obliterated by addition of $3 \mathrm{~g}$ isoleucine or by small amounts $(20 \mathrm{mg})$ of nicotinic acid and nicotinamide. In pharmacological doses these vitamins lower still further the brain serotonin and platelet concentrations, and it is suggested that this is due to the fact that serotonin present in a bound form in the storage granules is released and acted upon by monoamine oxidase ( $E C$ 1.4.3.4) (Krishnaswamy \& Ramana Murthy, 1970).

These changes are brought about in the two types of pellagrin (i.e. 'maize- and 'jowar-eaters') by a reduced availability of tryptophan for serotonin synthesis in the brain. However, the mechanism whereby this reduced availability of tryptophan is produced may not be the same.

Nicotinic acid is produced in the body from tryptophan via the kynurenine pathway. The rate-limiting enzyme in this pathway is hepatic L-tryptophan: oxygen oxidoreductase (EC 1.13.1.12), the activity of which is controlled by the amount of NADH in the tissue by a negative feedback process. In 'maize-eaters,' the low availability of nicotinic acid probably results in maximum metabolism of the small amount of tryptophan available via the kynurenine pathway and a consequent reduction in the tryptophan available for brain serotonin synthesis. In these patients, the fasting concentration of free tryptophan has been found to be significantly reduced (Truswell et al. 1968). In 'jowar-eaters,' leucine stimulates Ltryptophan:oxygen oxidoreductase and as a consequence tryptophan is again 'siphoned off' into the kynurenine pathway and the negative feedback may be overridden. The interactions of amino acid imbalance and nicotinic acid deficiency have been reviewed by Harper, Benevenga \& Wohlhueter (1970) and it has been suggested that imbalances of amino acids increase nicotinic acid requirements. The effect of leucine on L-tryptophan:oxygen oxidoreductase is counteracted by isoleucine, which has also been shown to improve the EEG of pellagrins with 
mental changes (Krishnaswamy \& Gopalan, 1971). Studies of the effects of leucine on plasma tryptophan levels suggest that the pellagragenic action of leucine is not mediated through changes in the circulating levels of tryptophan (Ghafoorunissa \& Narasinga Rao, 1975). The explanation of these apparent differences lies in the work discussed in the previous paper (Bender, 1978). For the uptake of tryptophan into the brain is only partially controlled by the plasma tryptophan concentration. It is affected by the plasma concentrations of other amino acids, including leucine, that compete for the same transport system into the brain. The concentrations of these amino acids is affected by other elements of the diet, particularly fat and carbohydrate.

These conclusions are tempting as an explanation of the psychiatric disturbances. However, as indicated previously, the situation is complex. Impaired pyruvic acid metabolism has been demonstrated in pellagrins with neurological disturbances (Bedi, Bomb, Agarwal, Bhatnagar \& Bedi, 1977) and both the biochemical abnormality and the clinical condition improve with nicotinic acid therapy. There is also some evidence for the involvement of pyridoxine in pellagra, at least in that produced by the consumption of jowar. Pyridoxine plays an important role in several steps of the kynurenine pathway, and thus stimulation of this pathway by excess dietary leucine could result in an increased requirement for the vitamin. There is indeed evidence that vitamin $B_{6}$ in large doses $(50 \mathrm{mg} / \mathrm{d})$ reverses some of the effects of leucine (Krishnaswamy, Bapu Rao, Raghuran \& Srikantia, 1976). Considered in conjunction with the lower pyridoxine content of jowar, it is therefore possible that in these pellagrins there is a situation analogous to that found in some women on combined oral contraceptives who develop depression and other mental disturbances that are corrected with pyridoxine supplements. The mechanism for the production of disturbances in these patients is thought to be the induction of L-tryptophan:oxygen oxidoreductase by oestrogens (Brumblatt \& Winston, 1970; Rose \& Braidman, 1970).

\section{Other conditions with pellagra-like symptoms}

I want now to return to those other conditions in which pellagra-like symptoms may develop. In Hartnup disease there is a primary disorder of amino acid transport resulting in malabsorption from the small intestine and in the renal tubules. The pellagra-like condition in this disease apparently results from the reduced availability of tryptophan for the synthesis of nicotinamide and NAD. The administration of nicotinamide $(40-250 \mathrm{mg} / \mathrm{d})$ results in considerable improvement of the dermatitis and neurological symptoms (Halvorsen \& Halvorsen, 1963 ). Pellagra occurs rarely in patients with the malignant carcinoid syndrome. In these patients dietary tryptophan is hydroxylated to 5-hydroxytryptophan and converted to serotonin in large amounts in tissues other than the brain (Sjoerdsma, Weissbach \& Udenfriend, 1956). Prolonged treatment with Isoniazid may lead to a pellagra-like psychosis and encephalopathy. It seems that it is only slow-inactivators of the drug that are prone to develop the condition 
(Devadatta, 1965) and may result from a deficiency of endogenous nicotinic acid synthesis coupled with a low intake of the vitamin.

\section{Psychiatric disorders}

The relationships of tryptophan and nicotinic acid metabolism to the psychiatric condition of pellagrins has stimulated interest in their possible involvement in other psychiatric disorders. Tryptophan has been used as an anti-depressant though some studies of its use have been inconclusive (Carroll, 1971; Mendels, Stinnett, Burns \& Frazer, 1975). Young \& Sourkes (1974) suggested that the weak or uncertain effect of tryptophan could be due to its metabolism by hepatic Ltryptophan:oxygen oxidoreductase. Since the activity of L-tryptophan:oxygen oxidoreductase is reduced by nicotinamide it seemed likely that the effectiveness of tryptophan in the treatment of depression would be increased by combined therapy. Studies in eleven newly-admitted depressed patients who were given increasing amounts of tryptophan and nicotinamide over 4 weeks (Chouinard, Young, Annable \& Sourkes, I977) have shown an encouragingly significant reduction of depression and the combination evidently warrants further investigation.

There is a strong genetic component in schizophrenia. Many biochemical studies have been performed on patients with this condition and suggestions for the involvement of nutrition in its aetiology include sensitivity to wheat gluten (Dohan, 1966; Singh \& Kaye, 1976) and a requirement for a very high intake of nicotinic acid. There is, indeed, evidence, principally of an anecdotal nature, that doses of nicotinic acid of $3 \mathrm{~g}$ or more/d may be of benefit in some patients with schizophrenia (Hawkins \& Pauling, 1973). A 'task force' set up by the American Psychiatric Association to investigate the effectiveness of megadoses of nicotinic acid vigorously opposed the therapy on the grounds of lack of properly-controlled trials. However, there are a number of important questions related to this that seem not yet to have been resolved. There seems little doubt that the schizophrenias are of multiple aetiology and there is then the problem of identifying the causative factor(s) in each patient (Dickerson, 1977). Furthermore, psychiatrists practising megavitamin therapy do not use it as a replacement for drug therapy, but as an adjunct to it. Moreover, nicotinic acid is not used alone but in combination with large amounts of other vitamins such as thiamin, pyridoxine and ascorbic acid.

\section{Conclusion}

The inter-relationships of tryptophan, nicotinic acid and amino acid imbalance are complex. Though some progress has been made in understanding their involvement via brain serotonin metabolism in the psychiatric disturbances of pellagra, depression and possibly of schizophrenia there are many gaps in our knowledge. These gaps include an understanding of the effects of imbalances of amino acids and of large amounts of vitamins on brain metabolism and function. 


\section{REFERENCES}

Bedi, H. K., Bomb, B. S., Agarwal, M. P., Bhatnagar, L. K. \& Bedi, T. (1977). Trans. Roy. Soc. trop. Med. Hyg. 71, 26.

Belavady, B., Srikantia, S. G. \& Gopalan, C. (1963). Biochem. 7. 87, 652.

Bender, D. (1978). Proc. Nutr. Soc. 37, 159.

Brumblatt, M. J. \& Winston, F. (1970). Lancet i, 832.

Carroll, B. J. (1971). Clin. Pharmac. Ther, 12, 743.

Chouinard, G., Young, S. N., Annable, L. \& Sourkes, T. L. (1977). Lancet i, 249.

Devadatta, S. (1965). Lancet ii, 440.

Dickerson, J. W. T. (1 977). Proc. Schizophrenia Ass. (In the Press).

Dickerson, J. W. T. \& Pao, S.-K. (1975). F. Neurochem. 25, 559.

Dohan, F. C. (1966). Acta Psychiat. scand. 42, 125.

Elvehjem, C. A., Madden, R. J., Strong, F. M. \& Woolley, D. W. (1937). J. Am. Chem. Soc. 59, I 767 .

Ghafoorunissa \& Narasinga Rao, B. S. (1975). Am. J. clin. Nutr. 28, 325.

Gopalan, C. \& Jaya Rao, K. S. (1975). Vitam. Horm, 33, 505.

Halvorsen, K. \& Halvorsen, S. (1963). Pediatrics, Springfield, 31, 29.

Harper, A. E., Benevenga \& Wohlhueter, R. M. (1970). Physiol. Rev. 50, 428.

Hawkins, D. \& Pauling, L. (editors) (1973). In Orthomolecular Psychiatry: Treatment of Schizophrenia. San Francisco: W. H. Freeman.

Krishnaswamy, K., Bapu Rao, M. D. S., Raghuran, T. C. \& Srikantia, S. G. (1976). Am. f. clin. Nutr. 29, 177 .

Krishnaswamy, K. \& Gopalan, C. (1971). Lancet ii, 1167.

Krishnaswamy, K. \& Raghuran, T. C. (1972). Life Sci. II, I191.

Krishnaswamy, K. \& Ramana Murthy, D. S. V. (1 970). Clinica chim. Acta 27, 301.

Mendels, J., Stinnett, J. L., Burns, D. \& Frazer, A. (1975). Archs gen. Psychiot. 32, 22.

Rose, D. P. \& Braidman, I. P. (1970). Lancet i, 1117 .

Singh, M. M. \& Kaye, S. R. (1976). Science, N.Y. 191, 401.

Sjoerdsma, A., Weissbach, M. S. \& Udenfriend, S. (1956). Am. Y. Med. 20, 530.

Srikantia, S. G., Reddy, M. V. \& Krishnaswamy, K. (1968). Electroenceph. clin. Neurophysiol. 25, 386.

Stahl, S. M. (1977). Archs gen. Psychia. 34, 509.

Truswell, A. S., Hansen, J. D. L. \& Wannenburg, P. (1968). Am. F. clin. Nutr. $21,1314$.

Wood, E. J. (1912). Treatise on Pellagra for the General Practitioner. New York: Appletons.

Young, S. N. \& Sourkes, T. L. (1974). Lancet ii, 897 .

Zambotti, F., Carruba, M., Vicentini, L. \& Mantegazza, P. (1976). Life Sci. 17, 1663. 